\title{
¿Qué hacemos con los pobres? El origen del Asilo de San Bernardino $(1834)^{1}$
}

Florentina Vidal GaLAche

Hasta bien entrada la Edad Moderna se consideraba al pobre como la encarnación de Cristo y la caridad como un medio para alcanzar la salvación eterna, siendo la Iglesia y los privilegiados los que tomaban a su cargo la ayuda a los necesitados, sin que el Estado discutiera estas competencias. Pero esta postura no excluia el que se adoptaran en contra de los mendigos actitudes de rechazo y control, especialmente en momentos de crisis -años de escasez de alimentos por malas cosechas, epidemias o guerras- en los que se organizaban redadas para alejarlos de los sitios públicos, donde su presencia se manifestaba ofensiva y no exenta de riesgos para el resto de la sociedad.

Fueron los ilustrados, con su ideal de estado rico, compuesto por ciudadanos útiles, los que dieron una nueva dimensión al mundo de la pobreza. Con sus planes de beneficencia favorecieron con medidas de asistencia y protección a los pobres honrados: trabajadores en paro, viudas, huérfanos, etc., a la vez que controlaban y reprimian a los picaros y vagos de oficio.

A partir del motín de Esquilache (1766) ${ }^{2}$, donde se utilizó a la gran masa de menesterosos para obstaculizar la voluntad real, los pobres fueron considerados no solamente una carga social y una llamada a las conciencias de los más favorecidos, sino un peligro latente para la seguridad del Estado. Es desde este momento cuando se inicia la clara represión

Sobre el Asilo de San Bernardino no existe bibliografia. Los interesados en la historia de la institución pueden consultar mi Tesis Doctoral: La beneficencia pública en Madrid en la primera mitad del siglo XIX. UNED, 1992, págs. 444-464.

"Véase de VILAR, P., "El motin de Esquilache y la crisis del Antiguo Régimen", Revista de Occidente, 107 (1972), págs. 199-249. 
hacia los mendigos, que pasan a ser tratados como verdaderos delincuentes, sin establecer distinciones entre unos y otros porque las propias leyes no definian bien los limites que separaban ambos grupos. En Madrid, tanto los pedigüeños como los auténticos malhechores, van a ser encerrados en el Hospicio ${ }^{3}$, donde vivirán en un claro régimen carcelario, con muy pequeñas diferencias en cuanto a trato y alojamiento ${ }^{4}$.

La sociedad liberal consideró teóricamente el problema del pauperismo desde una nueva óptica, dejando aparentemente a un lado la aptitud paternalista de sus antecesores. La Ley de Beneficencia de 1822 ofrecia a los menesterosos unas posibilidades sociales y unas consideraciones morales que los distinguia claramente de los verdaderos delincuentes, prohibiendo expresamente la reclusión de los pobres en el Hospicio por via de represión o castigo ${ }^{5}$. Pese a estas nobles declaraciones de principios los liberales continuaron ejerciendo la más cruel represión sobre los marginados madrileños.

\section{LA FUNDACIÓN DEL ASILO DE SAN BERNARDINO}

Durante los primeros años del siglo xix la Administración intentó, en varias ocasiones, la creación de otro centro de recogida de mendigos similar al Hospicio, ante el aumento progresivo en la capital de una infinita variedad de pedigüeños, inválidos sin recursos, niños sin hogar, rateros, mujeres de dudosa conducta y otros delincuentes menores. Generalmente en las etapas de sequia, crisis económicas o politicas, los inmigrantes pobres inundaban las calles de Madrid incrementando el número de menesterosos urbanos; entonces surgian planes concretos sobre la creación de nuevos centros donde acogerlos.

\footnotetext{
${ }^{3}$ El Hospicio del Ave Maria y San Fernando de Madrid fue creado en 1668 por la Congregación de esclavos del Ave Maria, para acoger a los pobres sin albergue. La bibliografia sobre esta institución se limita aun breve apartado en la obra de SoubeYroux, Jacques, "Pauperismo y relaciones sociales en el Madrid del siglo XVIII", Estudios de Historia Social x"I $x / m$ y $x x-x \times$ I. También hay una somera referencia a la historia del Hospicio en el articulo de VERDU Ruiz, Matilde, "El proceso constructivo del Hospicio del Ave Maria y San Fernando", A.I.E.M., t. X.

${ }^{4}$ En 1766 se creó en San Fernando de Henares un anexo del Hospicio de Madrid para encerrar a todos los revoltosos apresados trás el motin de Esquilache. En 1802 se cerró por falta de fondos y los reclusos pasaron al Hospicio del Ave María y San Fernando de Madrid donde se creó para el efecto un departamento de reclusión.

${ }^{5}$ Ley General de Beneticencia de 1822.
} 
La falta de medios económicos daba al traste con los sucesivos proyectos y los mendigos eran simplemente apartados de las calles y hacinados durante unos dias en el Hospicio, donde se les clasificaba y distribuia: a los forasteros se les devolvía a sus lugares de origen y a los pobres locales hábiles para el trabajo se les destinaba a las obras públicas o al ejército. Los incapaces de estas actividades, las mujeres sin recursos, los viejos y los niños desamparados quedaban encerrados en dicho establecimiento, la mayor parte de ellos hasta su muerte.

\section{¿QUÉ HACEMOS CON LOS POBRES?}

El acontecimiento que precipitó la creación del Asilo de San Bernardino fue la epidemia de cólera morbo sufrida por la capital en el verano de $1834^{\circ}$. Las noticias sobre esta enfermedad, desconocida en Europa hasta 1831, crearon un ambiente de pánico entre las autoridades españolas que sabian por experiencia que los pobres eran un peligroso medio de propagación de enfermedades. Tambien se temía que, si la epidemia llegaba a España, el terror y el desorden podian movilizar estas masas incontroladas en un levantamiento popular contra la Administración.

La expulsión de forasteros pobres, alrededor de 6.000 en dos años, se inició en 1832 con una de las habituales "recolecciones de mendigos"? Cuando estaba empezando la epidemia en Madrid, en el verano de 1834, se puso en marcha una nueva campaña para hacer desaparecer a todos los indigentes de las calles ${ }^{8}$.

- Sobre la asistencia y represión a los pobres durante la epidemia de cólera morbo de 1834 en Madrid cf: VIDAL GALACHE, Florentina, "La epidemia de cólera de 1834 en Madrid. Asistencia y represión a las clases populares", Espacio, Tiempo y Forma, UNED, 1989, págs. 271-279.

Las redadas para encerrar a los mendigos en el Hospicio eran habituales en Madrid desde la creación de éste y los liberales continuaron poniéndolas en práctica, a pesar de que en la Ley de Beneficencia de 1822 se señalaba que no debia encerrarse en este tipo de establecimientos a los pobres por via de represión o castigo

${ }^{8}$ El tres de julio de 1834 fue pasada una circular de la Real Orden de 30 de junio a todas las Diputaciones de Caridad, para que formaran el padrón de pobres de cada barrio, donde se decia: "Que todos los mendigos que infestan las calles de esta capital sean recogidos inmediatamente, obligados a trasladarse a su domicilio a los forasteros y se proporcionen alimento y trabajo a los naturales, a cuyo fin se formara en las parroquias una matricula o empadronamiento de los que por falta de medios de subsistencia tengan legitimo derecho a obtenerlos de la caridad pública...". En un primer momento fueron apresadas 351 personas -209 hombres y 143 mujeres-. "Actas de la Junta de Caridad de la Parroquia de San Sebastián, año 1834". Archivo de Villa. Sección Secretaria. 1-246-1. Acta de 6 de julio de 1834. 
El Hospicio ya se encontraba repleto y los responsables de la institución exigian el pago adelantado de un mes de estancia para admitir a nuevos asilados "; las condiciones fueron aceptadas por la Administración. A finales del mes de julio todo estaba dispuesto para recibir a los nuevos huéspedes ${ }^{10}$, pero en el último momento se cambiaron los planes y el 18 de septiembre los mendigos capturados fueron encerrados en el Convento de San Bernardino ${ }^{11}$, pasando los religiosos que lo habitaban al de San Cayetano.

El antiguo convento de San Bernardino, situado en la calle de su nombre, muy cerca del actual palacio de Liria, fue fundado en 1570 por los padres franciscanos - los denominados "padres Gilitos»-. Era un caserón destartalado que a principios del siglo xIx ya se había derrumbado en parte; sucesivos arreglos mejorarian algo su aspecto sin conseguir buenas condiciones de habitabilidad. Tenia un gran patio ajardinado, una huerta, dos comedores a los lados de la cocina, talleres y oficinas adosados en la parte izquierda del edificio y dormitorios a la derecha. Disponia de agua corriente, gran avance para la época, pero en la fecha de su puesta en función era un lugar poco a propósito para alojar a un colectivo de desgraciados integrado por hombres y mujeres de distintas edades y condición, junto a niños de ambos sexos ${ }^{12}$. Con todas sus deficiencias, el Asilo de San Bernardino se convertiría a lo largo del siglo xIx en uno de los más importantes «depósitos de pobres» de Madrid ${ }^{13}$.

El violento levantamiento popular del dia 17 de julio, que dio lugar a la matanza de frailes al atribuirles el populacho la contaminación de las aguas y la enfermedad reinante, debió apresurar los preparativos de encierro de los mendigos. El clima de peligro habitual en las calles de la capital se agravó extraordinariamente por estas fechas. El Gobierno temía que, con el pretexto de la epidemia, las revueltas pudieran impedir la deseada reunión de Cortes que iban a legalizar la sucesión de Isabel II

\footnotetext{
${ }^{9}$ Se exigia a la Administración dos reales y medio por individuo y dia.

${ }^{10}$ [Expediente instruido por el Ayuntamiento de Madrid y la Junta General de Caridad para encerrar a 351 pobres con ocasión de la epidemia de cólera morbo en la capital]. Archivo de Villa. Sección Corregimiento. 3-375-19.

11 R. O. de 30 de julio.

12 Curioso parlante (EL): “Una visita a San Bernardino», Semanario pintoresco Español, año 1836, pág. 156.

${ }^{13}$ El principal promotor del Establecimiento fue D. Joaquin Vizcaino, Viudo de Pontejos, que en el año 1834 ocupaba el cargo de Corregidor de Madrid.
} 
al trono, frente a las pretensiones del pretendiente D. Carlos, ya en guerra abierta contra los partidarios de Isabel ${ }^{14}$.

Para los gastos de instalación y mantenimiento del nuevo Asilo, el Gobierno adelantó solamente 100.000 reales, con la pretensión de que fueran las Diputaciones de Barrio, a través de cuestaciones entre los vecinos de la capital, las que realmente se encargaran de su financiación ${ }^{15}$.

El Asilo de San Bernardino estaba en clara desventaja con respecto a los demás instituciones benéficas públicas, ya que no contaba con más patrimonio que el edificio, e inició su andadura con limosnas concedidas por la reina y las suscripciones entre los vecinos de Madrid ${ }^{16}$. Más adelante los asilados contribuirian con el producto de su trabajo en los talleres de la Institución y los pocos que consiguieran trabajar fuera, en distintos oficios o como sirvientes domésticos, etc, debian dejar la mayor parte de sus salarios y limosnas obtenidas al Asilo. Pero la suma de todo ello no era suficiente para atender sus necesidades ${ }^{17}$ y era el Ayuntamiento, principal promotor de la fundación, el que se ocupaba de cubrir el déficit resultante ${ }^{18}$.

\section{EL TRABAJO DE LOS ASILADOS}

Con tan escasos recursos se pusieron en marcha talleres para que los asilados aprendieran un oficio y contribuyeran a mantener la casa; las mujeres realizaban labores de calceta, bordados, etc. Para los niños y niñas menores de 14 años habia escuelas de primeras letras y, llegados

${ }^{14}$ En la Real Orden de 18 de julio de 1834, promulgada al día siguiente de la matanza de frailes, se alertaba a la población en estos tèrminos: "La enfermedad que padece esta heroica Villa ...ha sido el pretexto de tales excesos; y los enemigos del trono de Isabel II, de su Augusta Madre y de la justa libertad, la verdadera causas...". El temor a las revueltas hizo difundir la noticia de que las "pasiones de ánimo" empeoraban el pronóstico de la enfermedad y se recomendaba, como medida preventiva, el conservar la calma y la serenidad ante cualquier circunstancia, sin dejarse llevar por sentimientos exaltados bajo ningún pretexto.

15 Curioso parlante ( $\left.E_{1}\right)$ : “Una visita...", pág. 158.

${ }^{16}$ En 1835 las limosnas Ilegaron a ser de 37.000 reales al mes. Cf.: Guía de Forasteros de 1834.

${ }^{17}$ En 1836 las suscripciones voluntarias alcanzaron los 27.000 reales al mes y los ingresos por trabajo de los pobres 4.000 reales aproximadamente, mientras que los gastos del mes de junio superaban los 34.766 reales. Cf.: Curioso PARLANTE (EL): "Una visita...", pág. 158.

${ }_{18}$ A partir de 1836 el Asilo, junto con los demás establecimientos de beneficencia pública, pasó a ser dirigido y administrado por el Ayuntamiento. 
a la edad de trabajar, simultaneaban la asistencia a éstas con el aprendizaje de algún oficio ${ }^{19}$. Los individuos de mejor conducta, los más aseados y correctos... y los que gozaban de la simpatia de los administradores se procuraban algún dinero con ciertas actividades fuera del asilo, actividades repetidamente calificadas de "agradables", como eran la de repartir sillas en las iglesias, asistir a los entierros en calidad de "acompañantes de los cortejos" y proporcionar lumbre, "dar candela", a los viandantes fumadores que no se querian molestar en encender sus cigarros ${ }^{20}$. En todas estas ocasiones los asilados iban acompañados de uno o más vigilantes, que informaban al administrador de su eficacia y evitaban las evasiones.

\section{LA DISCIPLINA Y LA VIDA COTIDIANA}

En las «redadas de mendigos" se apresaban tambièn a todos aquellos a los que su mísera apariencia hacia sospechosos de ejercer la mendicidad. La indiscriminación a la hora de realizar las recolecciones de pobres daba lugar, en ocasiones, a que se detuviera a gentes que no estaban pidiendo, pero que por su aspecto, sus vestidos, u otras circunstancias, resultaban sospechosos. Por ejemplo, todos los que deambularan por las calles en horas de trabajo.

Una vez en el Asilo se distribuia a los pobres en distintos departamentos: a los forasteros ${ }^{21}$ se les retenía solamente cuatro días o el tiempo necesario para obtener el pasaporte y devolverlos a sus obispados de origen $^{22}$. A los que demostraban que habian venido a la Corte a realizar

${ }^{19}$ En 1836 existian talleres de zapateros, sastres, carpinteros, herreros, torneros, tintoreros, ebanistas, pintores "a la oriental" $i$ ?, cerrajeros, esparteros y carreteros. Las manufacturas que salian de estos talleres no podian competir en el mercado por su baja calidad y, en los años estudiados (1834-1850), nunca reportaron beneficios al establecimiento. También se les procuró otros trabajos menores, como la numeración de las casas de Madrid a partir de 1834.

? A partir de 1842 el Asilo pasó a ser una sucursal del Hospicio, dentro de los planes establecidos por la Junta Municipal de Beneficencia para una mayor racionalización de los distintos centros madrileños. Desde entonces el Director del Hospicio lo fue también del Asilo.

${ }^{21}$ En esta etapa se consideraba forasteros a todos aquellos que residieran en la capital menos de siete años.

"Si después de obtenido el pasaporte los forasteros volvian a ser vistos mendigando por Madrid, eran detenidos y devueltos a su lugar de origen por la justicia; si reincidian, debian ser puestos a disposición del juez de primera instancia, es decir se les consideraba ya como delincuentes. 
"diligencias propias», o a buscar trabajo, se les ponia en libertad, si tenían medios para vivir.

Los naturales de Madrid no podian salir sin antes probar que tenian un oficio que les permitiera vivir sin mendigar, $y$ en el caso de ser menores de 14 años los padres o tutores debian demostrar que podian mantenerlos y comprometerse a impedir que reincidieran.

A las mujeres se les permitia abandonar el establecimiento siempre que sus maridos pudieran mantenerlas y el alcalde de su barrio diera un informe favorable su conducta.

Los que salian bajo estas condiciones y eran sorprendidos mendigando de nuevo, volvian a ser encerrados sin que pudieran ya abandonar el Asilo bajo ningún pretexto y corriendo la manutención a su cargo, si tenían medios para ello o familiares que los sufragaran. Está claro que se trataba de un internamiento forzoso y costeado además por el propio infractor.

Si alguno de los internados tenía que abandonar el centro por motivos graves era indispensable el permiso del Director, que le fijaba las horas de salida y regreso; para pasar la noche fuera necesitaban el visto bueno del Corregidor ${ }^{23}$.

Al igual que en el Hospicio, el control sobre los mendigos y la carencia de libertad eran totales, pero existian aqui aspectos más negativos, evidentes en la forma de castigar las infracciones al Reglamento. Con especial rigor se penalizaban cualquier actitud de rebeldia contra los empleados y vigilantes, la mayoria reclutados entre los propios asilados con las consecuencias lógicas de envidias, recelos y delacciones que este régimen propiciaba ${ }^{24}$. La desobediencia era castigada con 24 horas de encierro en la sala de corrección y si iba acompañada de injurias o palabras deshonestas, con tres dias en el calabozo aislado; si se habia opuesto resistencia activa la pena subia a ocho dias de calabozo y sufrimiento del "saco de fuerza" $i . . . ?$ todo el tiempo que el administrador considerara oportuno, que solia ser de varias horas.

\footnotetext{
${ }^{23}$ Vizcaino, Joaquin, Reglamento provisional del Asilo de Mendicidad de San Bernardino. Madrid 1836. Cap. 1. Arts. 1 y 2.

${ }^{24}$ Los mendigos de San Bernardino estaban organizados en brigadas y éstas en escuadras compuestas entre diez y quince personas. Al mando habia un brigada y dos cabos. elegidos por el administrador entre los mismos asilados. Las brigadas de mujeres estaban dirigidas por una celadora. Cada brigada realizaba una tarea especifica. Estos mandos, escogidos entre los de mejor conducta, aplicación y cualidades, estaban exentos del servicio mecánico interior y recibia en pago dos cuartos diarios. Cf. Vizcaino, J., "Reglamento...». cap. II.
} 
La falta de aseo, pereza en el trabajo, defectos en el cumplimiento del servicio, salida del edificio sin licencia, embriaguez y hurto de algún efecto eran penalizadas de distintas maneras. Los castigos podian acumularse en función de las faltas cometidas, por ejemplo se privaba del recreo a los internos que hicieran sus necesidades naturales fuera del lugar destinado al efecto; si además pintaban las paredes con dibujos, escritos, o escupian en ellas, tampoco podrian salir del establecimiento el domingo; si en un exceso de maldad llegaban a ponerse de pie sobre las camas o se acostaban con los zapatos puestos, no se lavaban manos y cara a diario, ni los pies una vez a la semana, a las penas ya mencionadas se añadiria la privación de un "servicio agradable", como el de acompañar a los entierros. Si a su perversidad añadian la molesta costumbre de cortar maderas, puertas, bancos u otros muebles o se les ocurriera picar tabaco encima de ellos se quedarian además sin recreos, sin salida, recargados en su trabajo y a dieta de pan y agua.

Pero sobre todo se castigaba la insubordinación y con el máximo rigor la insubordinación en grupo: cualquier negativa a trabajar hecha por más de tres individuos en un mismo taller era castigada con encierro en el calabozo aislado y paso por la sala de "corrección", donde se utilizaban instrumentos de tortura como la "rueda de fuerza", el "saco de fuerza" y otros que no se definen pero que estaban previstos para los reincidentes. El "calabozo negro" se reservaba para los que cometian acciones deshonestas. Aquellos asilados incorregibles, o que cometieran algún delito mayor que los enunciados, se les formaba proceso verbal y se les enviaba como delincuentes ante el juez.

Los mendigos de buena conducta recibian algunas recompensas como una mención honorifica en la lista general, permiso de salida, ascenso a jefe de brigada, pequeñas cantidades en metálico y los ya repetidos destinos en "servicios agradables" ${ }^{25}$; unos premios poco atractivos en comparación con los graves castigos previstos.

\section{LA JORNADA DIARIA}

El horario establecido permitía pocos ratos de asueto. En verano se levantaban a las cuatro y media de la mañana y en invierno una hora

\footnotetext{
" Idem, capítulo VIII: penas y recompensas; capitulo III: Distribución del tiempo; capitulo IV: Trabajo y ocupación de los pobres.
} 
más tarde; los remisos a dejar las sábanas, que suponemos debian ser bastantes dado lo impropio del horario, eran castigados sin recreo uno o varios dias, incluso los domingos, dependiendo del grado de pereza. Despues de asearse y desayunar iniciaban el trabajo: los hombres en los talleres, la huerta, llevando a los enfermos al hospital, tareas externas, etc. Las mujeres se ocupaban del aseo de la casa, la cocina, la colada o las labores de costura para fuera.

A la doce comían y dormian la siesta $i . .$. ?; a las tres volvian a trabajar hasta las siete de la tarde, y desde esta hora hasta la cena se les ocupaba en lecturas o ejercicios piadosos, clases o cualquier otra distracción inofensiva. La cena se tomaba a las nueve, se pasaba lista, hacian la cama (un petate que permanecía recogido por el día) y se acostaban.

No se permitian juegos de azar —naipes, dados, etc-. También estaba prohibido cantar, el consumo de bebidas alcohólicas se penalizaba con ocho dias de calabozo a pan y agua, y existía otro castigo, de uno a cuatro dias de encierro en la sala de corrección, para los que turbaran el orden de los patios con gritos, juegos ruidosos "u otros excesos". Realmente resulta dificil adivinar a qué distracción agradable podian dedicar su ocio los pobres del Asilo, analfabetos todos o casi todos, que no tenian tampoco el consuelo de la lectura; sin duda podian organizar interesantes tertulias, siempre en tono educado y comedido y con el debido respeto, pues estaba formalmente prohibido y penado, con privación de cuatro dias de recreo, el tuteo y el uso de apodos entre la población reclusa ${ }^{26}$.

Todas las actividades de los muchachos - recibian enseñanza de primeras letras y asistian a talleres con horario similar a los adultos- comenzaban con un redoble de tambor y sus desplazamientos por el asilo debian hacerlos en fila de a dos, por brigadas y en silencio, con sus respectivos jefes a la cabeza. Las niñas tenía el extraordinario privilegio de poder pasear por la huerta, despues de las comidas. Habia una absoluta separación de sexos, con vigilantes y celadoras a la puerta de los dormitorios. Estaba prohibido el castigo corporal a los niños.

La jornada dominical no ofrecia grandes alicientes. Se levantaban una hora más tarde y tras la limpieza de dormitorios e inspección de ropas por el administrador, pasaban a la capilla para la Misa y lecturas piadosas. El resto de la mañana estaba dedicado a recibir a los familiares. Por la tarde, paseo en grupo y bajo vigilancia; el que quisiera podia volver a

\footnotetext{
${ }^{26}$ No conocemos los castigos que se imponian a los pobres del Hospicio, pero algunos autores aseguran que el régimen del Asilo era menos penoso. Es de suponer que también hubiera en el Hospicio máquinas de castigo.
} 
la capilla que permanecia abierta y donde mediada la tarde se celebraba el rezo del Rosario.

Poca diferencia debia existir entre el régimen seguido en San Bernardino y el de las cárceles, ya que la falta de libertad, la represión, los castigos $e$ incluso los tormentos se ejercian en el Asilo.

\section{LA LIMPIEZA}

En una época en que las medidas higiénicas eran lamentables, incluso entre las clases privilegiadas, no son de extrañar las noticias que en este sentido hemos recabado de aquel depósito de miserables madrileños que fue el Asilo de San Bernardino.

Del barrido y limpieza de los aposentos se ocupaban las mujeres, que también tenian a su cargo el lavado y "colada" de las ropas. Los dormitorios, comedores y demás piezas se blanqueaban una vez al año y se barrian diariamente, dejando para el sábado una limpieza especial. Se insistía mucho en que dormitorios, comedores y talleres tuvieran las ventanas abiertas, una saludable medida que tenia el inconveniente de hacer los aposentos poco confortables durante el crudo invierno madrileño.

Al ingreso en el establecimiento cada uno de los acogidos debía entregar todas sus pertenencias, ijoyas! y armas en especial. Después se les cortaba el pelo y eran obligados a «lavarse todo el cuerpo", lo que suponía la existencia de baños que no volvían a utilizarse de forma habitual.

Los hombres recibian un traje de paño pardo, con botones blancos con el nombre del Asilo, dos pantalones, tres camisas de lienzo, una gorra y un par de zapatos que completaban el atavio de andar por casa. Para la calle llevaban un estrambótico uniforme compuesto de blusón fruncido a las caderas por un cinturon embreado, adornado de inmensa hebilla, y en la cabeza un enorme sombrero de copa, de tela también embreada, en el que figuraba el nombre del establecimiento y el número de serie del portador. Sin lugar a dudas su presencia no pasaria inadvertida en las calles de Madrid. En este equipo no figuraba ropa interior alguna. Para los jergones de paja de los dormitorios disponian de dos sábanas y dos mantas «berrendas".

El ajuar de las mujeres se componia de jubón y saya de estameña, con un escudo en el brazo izquierdo que incluia el nombre del establecimiento y el número de serie, dos sayas bajeras ordinarias, tres cami- 
sas, un ajustador, dos pares de medias, dos paños, dos delantales, un par de zapatos y los inevitables pañuelos de cabeza que aparecen indefectiblemente en el atuendo de todas las internas de establecimentos benéficos. Se echan en falta prendas hoy indispensables de ropa interior. Los niños llevaban idéntico vestuario y todos recibian un peine y un cepillo.

Cada brigada, entre diez y quince personas, disponian para el aseo diario de un espejo y cuatro paños de mano. Por la mañana procedian a peinarse y lavarse cara y manos en el pilón del patio. Los pies y la cabeza estaba mandado que se lavara una vez a la semana, las uñas debian cortarse con la misma frecuencia y el pelo cuando fuera necesario.

Las sábanas y fundas de almohada se renovaban una vez al mes y las camisas se cambiaban cada semana. El resto del vestuario sólo se cambiaba en caso de necesidad. En el supuesto de enfermedad contagiosa se fumigaban y desinfectaban habitaciones y enseres con vapores de cloro y se quemaban las ropas. Tan someras medidas higiénicas no precisan comentario y se puede imaginar lo incómodo del ambiente de estos establecimientos, donde se amontonaban personas de distintas edades y condiciones compartiendo lacras y suciedad ${ }^{27}$.

\section{LA COMIDA}

En San Bernardino los asilados se lavaban poco pero comían menos. Su dieta, compuesta casi exclusivamente de pan y legumbres, con una presencia casi testimonial de carne reducida a tres cabezas de carnero por arroba de patatas, era la más pobre de todos los establecimientos de beneficencia de la época en la capital y sólo comparable a la del Hospicio.

Para el almuerzo, primera comida del dia, se les daba una sopa de ajo, condimentada con pimentón, aceite y pimiento, donde se desmigaba un cuarterón de pan. A mediodia tomaban un potaje con verdura, patatas cabezas de carnero y grasas animales en proporción del $5 \%$ del peso total de los ingredientes empleados (los dias de vigilia se usaba solamente aceite). Para la cena habia otro potaje con verduras, patatas y media libra de pan. El menú se alteraba solamente en las grandes ocasiones ${ }^{28}$.

\footnotetext{
${ }^{27}$ Idem, Cap. VI. Aseo y salubridad.

${ }^{24}$ Idem, capitulo X: Disposiciones generales.
} 
Esta dieta deficiente en vitaminas, calcio, sales minerales y sobre todo de proteinas de calidad, se ofrecía a niños desde los siete años, hombres y mujeres adultos que desarrollaban un trabajo variado, y tambien a los ancianos achacosos. Cada uno de estos grupos tenia distintas necesidades energéticas que en ningún caso llegaba a cubrirse.

Tanto el Hospicio como el Asilo de San Bernardino, más que establecimientos de ayuda al necesitado fueron centros de represión, verdaderas cárceles utilizadas para apartar de las calles a todos aquellos marginados que estorbaban a la sociedad.

Pese a sus aspectos negativos, que incluia un régimen donde no faltaban los tormentos corporales, el Asilo de San Bernardino era solicitado por muchos pobres. La miseria presente en la capital de España en esta etapa, con más de la mitad de la población próxima o inmersa en la pobreza, hacia deseable para los más desposeidos este albergue de características impensables para nuestra mentalidad.

No obstante hubo ocasiones en que la capacidad de sufrimiento de aquellos desgraciados se vio desbordada, dando lugar a actitudes violentas; el 17 de enero de 1835 los pobres de San Bernardino se amotinaron ${ }^{29}$, escapando tumultuosamente a la calle y llenando de consternación al pueblo de Madrid, principal benefactor del Asilo, que cómodamente ignoraba la situación de sus uprotegidos». Un año después, la prensa daba una visión idílica de la vida del establecimiento ${ }^{30}$, acallando las conciencias de los ciudadanos que volvieron a respirar tranquilos sabiendo a sus pobres bien encerrados y convenientemente atendidos.

\footnotetext{
${ }^{29}$ Véase en el Diario de Avisos de Madrid del 17 de enero de 1835.

30 Cf.: Curioso parlante (EL): Una visita..., págs. 158-159.
} 